\title{
Neonatal Intestinal Perforation-A Rare Complication of Small Bowel Hemangioma
}

\author{
Nasser Shukri ${ }^{1}$ Ridha Amara ${ }^{1}$ Shakeel Malik ${ }^{1}$ Hanan Taher $^{1}$ Mansour Kilany ${ }^{1}$ \\ ${ }^{1}$ Department of Pediatric Surgery, Maternity and Children's Hospital, \\ Jeddah, Saudi Arabia \\ Address for correspondence Nasser Shukri, FRCS, Department of \\ Pediatric Surgery, Maternity and Children's Hospital, PO Box 14663 , \\ Jeddah 21434, Saudi Arabia (e-mail: nas007_sa@hotmail.com).
}

Eur J Pediatr Surg Rep 2013;1:30-31.
Abstract
Keywords
- neonate
- ileal
- perforation
- hemangioma

Intestinal perforation is an extremely rare complication of hemangioma of the small intestine in the neonatal period. This is a case report of a 27-days-old male infant who presented with signs and symptoms of acute intestinal obstruction. Exploratory laparotomy findings revealed intestinal perforation due to solitary hemangioma in the ileum, which led to obstruction from peritoneal reaction and adhesions. There are two reported cases in the literature presenting with ileal perforation in the pediatric age group, but only one previous report mentioned in the neonatal period. Because there are other more common causes of perforation in the neonatal period, intestinal hemangioma in spite of its rarity should be included in the differential diagnosis.

\section{Introduction}

Neonatal intestinal perforation (NIP) is an extremely rare complication of intestinal hemangioma $(\mathrm{IH})$. Neonates younger than 30 days and having perforation include more common etiologies such as necrotizing enterocolitis, meconium ileus, and spontaneous idiopathic as well as gastric perforation. ${ }^{1}$ NIP has been associated with mortality rates of $40 \%$ to $70 \%{ }^{2}$ This report presents a rare case of NIP resulting from IH.

\section{Case Report}

A 27-day-old male neonate was admitted with low-grade fever, abdominal distension, and bilious vomiting associated with bouts of diarrhea of 2 days duration. Baby was a product of full-term spontaneous vaginal delivery with normal prenatal follow-up. Before coming to our hospital, the infant had been treated as gastroenteritis in other hospitals. On admission, the patient weighed $4.1 \mathrm{~kg}$ and was febrile, irritable, and moderately dehydrated. Abdominal examination revealed marked distension with mild tenderness in the paraumbilical region. Laboratory investigations showed hemoglobin $12 \mathrm{~g} / \mathrm{dL}$ and leukocyte $15,000 \mathrm{c} / \mathrm{mm}$. Other laboratory investigations were unremarkable. Plain abdominal radiographs suggested bowel obstruction versus ileus, therefore a barium meal follow through was obtained, which showed persistently dilated jejunal and proximal ileal loops but normal flow of contrast. Computed tomographic scan with intravenous contrast was not done because of family history of allergic reaction to the dye. On the basis of the diagnosis of intestinal obstruction, a decision for exploratory laparotomy was made.

Laparotomy revealed dense inflammatory adhesions surrounding a solitary hemangioma located at the antimesenteric border $30 \mathrm{~cm}$ from the ileocaecal valve and on close inspection a small perforation was seen on one side of the hemangioma, which was sealed by extensive adhesions ( - Fig. 1). There was minimal contamination of the peritoneal cavity. Other areas of the bowels inspected were normal and resection with primary anastomosis was done.

Histopathological examination of the surgical specimen revealed capillary hemangioma ( - Fig. 2). Postoperative period was uneventful and the patient was discharged on the 10th day.

\section{Discussion}

Hemangiomas of the gastrointestinal tract are rare and account for only $0.05 \%$ of all intestinal neoplasms. ${ }^{3}$ They are commonly found within the small bowel, jejunum being the received

October 19, 2012

accepted after revision

December 4, 2012

published online

March 19, 2013 (c) 2013 Georg Thieme Verlag KG Stuttgart · New York
DOI http://dx.doi.org/ 10.1055/s-0033-1337110. ISSN 2194-7619. 


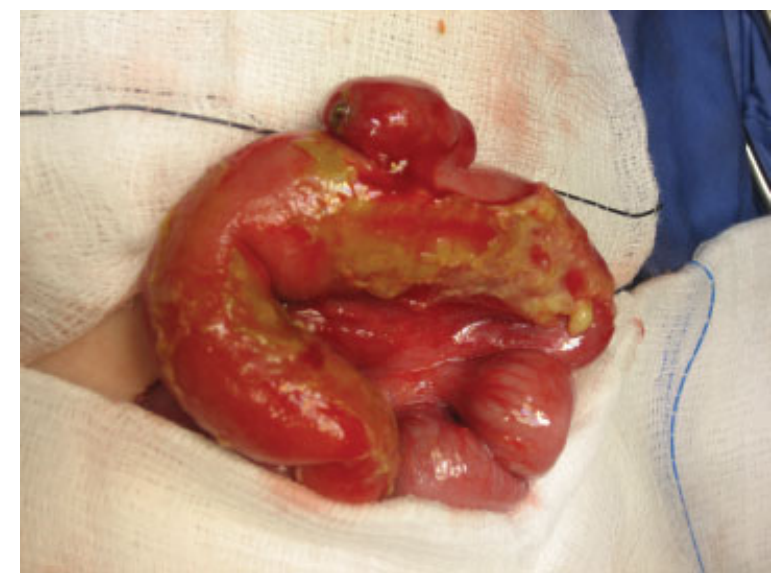

Fig. 1 Solitary ileal hemangioma with perforation site.

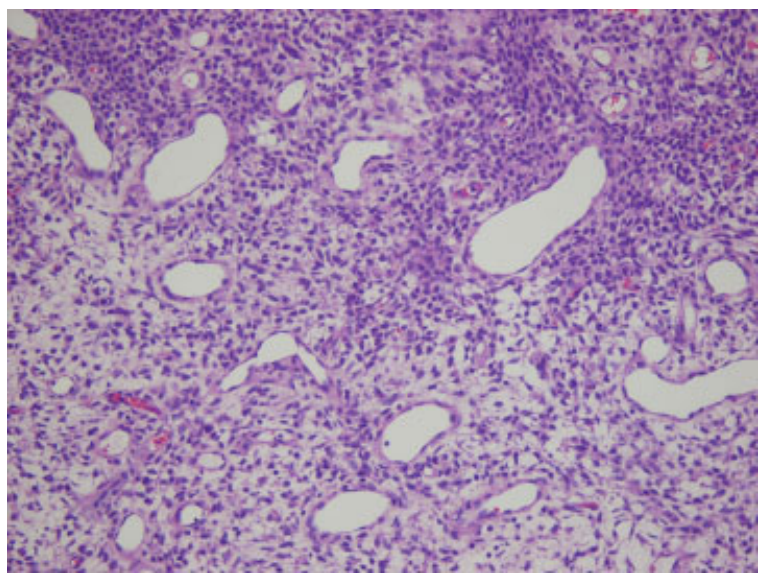

Fig. 2 Dilated capillary spaces lined by single layer of endothelium with proliferation of endothelial cells in between.

commonest site and compose 7 to $10 \%$ of all benign tumors. ${ }^{3,4}$ They have a tendency toward multiplicity, with solitary tumors being extremely rare. ${ }^{3,5}$ Microscopically, IH may be classified as cavernous, capillary, or mixed types, commonest being the cavernous. ${ }^{6}$ The usual presentation is intestinal bleeding usually insidious presenting as anemia ${ }^{7}$ or sometimes acute and potentially life threatening. ${ }^{4}$ Other forms of rare presentation include intussusception, obstruction, and perforation. ${ }^{8-10}$

Ileal perforation is a rare complication of $\mathrm{IH}$ in neonates, and so far, only one case has been reported in the literature, by McGaughey et al, ${ }^{11}$ who discovered evidence of ileal perforation due to IH while operating on a neonate with intestinal obstruction. Ours is the second reported case of NIP due to IH, and what makes it unique is the fact that the hemangioma belonged to the rare capillary type whereas the previously reported case was of the commoner cavernous type. Diagnosis in both reported cases, including ours, were made only at surgery for presumed acute intestinal obstruction.
Although various causes of NIP including the rare IH have been reported, diagnosis can be difficult and exploratory laparotomy has often proved to be the final diagnostic tool.

\section{Conclusions}

Although a rare cause of intestinal perforation in neonates, $\mathrm{IH}$ should be considered in the differential diagnosis.

\section{Acknowledgements}

We wish to express special thanks to Dr. Hanan Al Khateeb and Dr. Soha Al-Tamimi from the Histopathlogy department, also to Dr. Fatma Al-Aqeil, Dr. Osama Abu Ghazala, and Dr. Yasser Sabry for their cooperation in this case study.

\section{Conflict of Interest}

None

\section{References}

1 Asabe K, Oka Y, Kai H, Shirakusa T. Neonatal gastrointestinal perforation. Turk J Pediatr 2009;51(3):264-270

2 St-Vil D, Le Bouthillier G, Luks FI, Bensoussan AL, Blanchard H, Youssef S. Neonatal gastrointestinal perforations. J Pediatr Surg 1992;27(10):1340-1342

3 Boyle L, Lack EE. Solitary cavernous hemangioma of small intestine. Case report and literature review. Arch Pathol Lab Med 1993;117(9):939-941

4 Levy AD, Abbott RM, Rohrmann CA Jr, Frazier AA, Kende A. Gastrointestinal hemangiomas: imaging findings with pathologic correlation in pediatric and adult patients. AJR Am J Roentgenol 2001;177(5):1073-1081

5 Morgan DR, Mylankal K, el Barghouti N, Dixon MF. Small bowel haemangioma with local lymph node involvement presenting as intussusception. J Clin Pathol 2000;53(7):552-553

6 Corsil A, Ingegnolil A, Abelli P, et al. Imaging of a small bowel cavernous hemangioma: report of a case with emphasis on the use of computed tomography and enteroclysis. Acta Biomed 2001;78: 139-143

7 Magnano A, Privitera A, Calogero G, Nanfito' L, Basile G, Sanfilippo G. Solitary hemangioma of the small intestine: an unusual cause of bleeding diagnosed at capsule endoscopy. J Pediatr Surg 2005;40: E25-E27

8 Singh BP, Kumar A, Chattopadhyay TK. Intussuscepting ileal hemangioma with perforation. Indian J Gastroenterol 1992;11(2): 94-95

9 Kella N, Rathi PK, Rathi S, et al. Small bowel haemangioma. A rare cause of intestinal obstruction in infant. Pak J Med Sci 2008;24 (4):629-631

10 Rao AB, Pence J, Mirkin DL. Diffuse infantile hemangiomatosis of the ileum presenting with multiple perforations: a case report and review of the literature. J Pediatr Surg 2010;45(9): 1890-1892

11 McGaughey HR, Hosie RT. Intestinal obstruction and intra-abdominal calcification in the newborn following rupture of a hemangioma of the bowel. Canad Med Assoc J 1966;95(9):414-415 